\title{
Ultrasound-Assisted Lipoplasty: The Ad Hoc Situation
}

\author{
Constance Neuhann-Lorenz
}

Received: 11 November 2008/Accepted: 18 November 2008/Published online: 3 February 2009

(C) Springer Science+Business Media, LLC and International Society of Aesthetic Plastic Surgery 2009

The article by Roustaei et al. [1] about the safety and value of ultrasound-assisted liposuction (UAL) is somewhat too enthusiastic so that the results and their relationship to numerous previous evaluations should not be left without some additional remarks. The safety and relevance of UAL compared with conventional liposuction techniques has been studied and evaluated by various authors [2] over more than 10 years, mostly in the U.S. between 1997 and 2003 after the first reports more than 5 years earlier from Europe. The outcome of this Iranian study, where the UAL technique had not been available earlier, describes an extremely low complication rate even although a statistically relevant number of cases is evaluated. This desirable outcome may be due to the fact that only one surgeon performed the procedures. Such consecutive experience always provides useful insight in the critical evaluation of a technique and its reproducibility.

The conclusions of the authors, however, do not adequately represent the actual situation of use of UAL by plastic surgeons in Europe or the U.S. Although the authors cited some of the most important publications on UAL versus other liposuction techniques, the results of these publications are not implemented completely. Among others in the cited article Blondeel et al. [3] conclude that "UAL is, therefore, probably more beneficial to the surgeon than to the patient. The financial investment in the device is justified for surgeons with large liposuction practices, mainly, and probably solely, because of the reduced physical strain for the surgeon." The latest overview in liposuction techniques, including the various UAL devices, by Jewell [4] last year defines the actual state of the art in liposuction techniques and the need for further research and studies.

The conclusion of the authors that "The additional benefits of the UAL technique combined with fewer local complications and no SAEs, compared with other liposuction techniques (TL and SAL), suggest that it may become a more widely used modality in liposuction surgery" does not meet these long-term goals and should be considered critically.

\section{References}

1. Roustaei N, Lari SJM, Chalian M, Chalian H, Bakhshandeh H (2009) Safety of ultrasound-assisted liposuction: a survey of 660 operations. Aesthetic Plast Surg 33. doi:10.1007/s00266-0089293-9

2. Maxwell GP, Gingrass MK (1998) Ultrasound-assisted lipoplasty: A clinical study of 250 consecutive patients. Plast Reconstr Surg 101:189

3. Blondeel PN, Derks D, Roche N, Van Landuyt KH, Monstrey SJ (2003) The effect of ultrasound-assisted liposuction and conventional liposuction on the perforator vessels in the lower abdominal wall. Br J Plast Surg. 56:266-271

4. Jewell M (2008) Lipoplasty. In: Eisenmann-Klein M, NeuhannLorenz C (eds), Innovations in Plastic and Aesthetic Surgery. New York: Springer, chapter 55, pp 443-453 